\title{
Impact of Socioeconomic Factors and Gender on Refill Adherence and Persistence to Lipid-Lowering Therapy in Type 1 Diabetes
}

\author{
Christel Hero (1) - Sofia Axia Karlsson · Stefan Franzén · \\ Ann-Marie Svensson - Mervete Miftaraj · Soffia Gudbjörnsdottír · \\ Karolina Andersson-Sundell $\cdot$ Björn Eliasson $\cdot$ Katarina Eeg-Olofsson
}

Received: March 14, 2021 / Accepted: July 6, 2021 / Published online: July 22, 2021

(C) The Author(s) 2021

\section{ABSTRACT}

Introduction: Lipid-lowering therapy (LLT) reduces the risk of cardiovascular disease (CVD) in patients with type 1 diabetes (T1D). However, socioeconomic factors and gender may have an

Supplementary Information The online version contains supplementary material available at https:// doi.org/10.1007/s13300-021-01115-w.

C. Hero · A.-M. Svensson · S. Gudbjörnsdottír · B. Eliasson $\cdot$ K. Eeg-Olofsson

Department of Molecular and Clinical Medicine, Sahlgrenska Academy, University of Gothenburg, Gothenburg, Sweden

C. Hero $(\bowtie) \cdot$ B. Eliasson · K. Eeg-Olofsson

Department of Medicine, Sahlgrenska University Hospital, 41345 Gothenburg, Sweden e-mail: christel.hero@vgregion.se

S. A. Karlsson · K. Andersson-Sundell Department of Public Health and Community Medicine, Sahlgrenska Academy, University of Gothenburg, Gothenburg, Sweden

S. Franzén · A.-M. Svensson · M. Miftaraj ·

S. Gudbjörnsdottír

National Diabetes Register, Centre of Registers

Västra Götaland, Gothenburg, Sweden

S. Franzén

Health Metrics Unit, Sahlgrenska Academy,

University of Gothenburg, Gothenburg, Sweden

K. Andersson-Sundell

Medical Evidence and Observational Research, Astra

Zeneca AB, Gothenburg, Sweden impact on the adherence to and non-persistence with LLT.

Methods: This was a nationwide register-based cohort study that included 6192 individuals with T1D aged $\geq 18$ years who were registered in the Swedish National Diabetes Register and had initiated novel use of LLT. Information on socioeconomic parameters (source: Statistics Sweden) and comorbidity (source: National Patient Register) was collected. The individuals were followed for 36 months, and adherence to LLT was analyzed according to age, socioeconomics and gender. The medication possession ratio (MPR; categorized into $\leq 80 \%$ and $>80 \%$ ) and non-persistence (discontinuation) with medication was calculated after 18 and 36 months.

Results: Individuals older than 53 years were more adherent to LLT (MPR > 80\%) than those younger than 36 years (odds ratio [(OR] 1.30, $p<0.0001)$ at 36 months. Women were more adherent and less prone to discontinue LLT at 18 months (OR 1.05, $p=0.0005$ and OR 0.95, $p=0.0004$, respectively), but not at 36 months. Divorced individuals were less adherent than married ones (OR 0.93, $p=0.0005$ ) and discontinued LLT more often than the latter (OR 1.06, $p=0.003)$. Education had no impact on adherence, but individuals with higher incomes discontinued LLT less frequently than those with lower incomes. Individuals with a country of origin other than Sweden discontinued LLT more often. 
Conclusion: Lower adherence to LLT in individuals with T1D was associated with male gender, younger age, marital status and country of birth. These factors should be considered when evaluating adherence to LLT in clinical practice, with the aim to help patients achieve full cardioprotective treatment.

Keywords: Adherence; Persistence; Socioeconomy; Socioeconomic status; Lipid-lowering therapy; Statin therapy; Type 1 diabetes

\section{Key Summary Points}

Low adherence to lipid- lowering therapy is of major concern when the aim is to prevent cardiovascular disease (CVD) in individuals with type 1 diabetes (T1D).

Sociodemographic factors may be part of the explanation for low adherence behavior.

In this study we show that low adherence was associated with male gender, younger age, marital status, country of birth and being a smoker, while individuals with higher incomes less frequently discontinued therapy for dyslipidemia.

These findings illuminate the importance of addressing adherence to treatment at every clinical visit to ensure full cardiovascular protection in individuals with T1D at risk for CVD.

\section{INTRODUCTION}

Cardiovascular disease (CVD) is a major cause of death in type 1 diabetes (T1D). Advances in diabetes care over the past decades have narrowed but not closed the gap in life expectancy between patients with T1D and the general population [1]. Australian mortality data between 1997 and 2010 on patients with T1D showed a loss of life expectancy of 12.2 years compared to the general population at age $\geq 40$ years, mainly due to CVD [2]. A recently published observational cohort study from Sweden found that early onset of T1D is associated with a higher risk of cardiovascular complications and a shorter lifespan than a later onset, resulting in a loss of 17.7 life years in women and 14.2 life years in men compared to the general population [3].

To reduce the risk of developing cardiovascular complications, current guidelines recommend aggressive management of risk factors. This includes control of dyslipidemia with dietary as well as pharmacological interventions. The 2019 European Society of Cardiology/European Atherosclerosis guidelines on management of dyslipidemia recommend that individuals with T1D with disease duration of $\geq$ 10 years or with additional cardiovascular risk factors should have a goal for low-density lipoprotein (LDL)-cholesterol of $1.8 \mathrm{mmol} / \mathrm{l}$ and/or $\mathrm{a} \geq 50 \%$ decrease in their LDL-cholesterol [4]. In the recently updated Standards of Diabetes Care from the American Diabetes Association, the guidelines recommend lifestyle intervention and statin treatment of dyslipidemia in individuals with T1D, particularly in those aged $>40$ years or with signs of microvascular complications, but also suggest that statin therapy be considered for T1D patients aged 20-39 years if cardiovascular risk factors are present [5]. Hence, individuals with T1D are often considered for cardioprotective drugs, such as lipid-lowering therapy (LLT), earlier in life than the general population at large. Treatment with HMG CoA-reductase-inhibitors (statins) has shown good effect in reducing cholesterol levels, as well as decreasing morbidity and mortality from CVD in diabetes [6]. Observational data from the Swedish National Diabetes Register show that LLT lowers the risk for CVD and death in T1D patients without previous CVD [7].

However, due to suboptimal adherence and persistence to LLT, the protective effects of statin treatment seen in randomized controlled trials may be less pronounced in real life outside of the boundries of clinical trials. The World Health Organization has earlier addressed the issue of adherence and persistence to medication for chronic diseases and found that low 
adherence is not only common, but also has large implications for health outcomes [8]. Several studies have confirmed suboptimal adherence and persistence to LLT in a real-world setting, both in the treatment of dyslipidemia in the general population and in individuals with diabetes $[9,10]$. It has also been shown that low adherence and non-persistence to LLT leads to increased risk of cardiovascular events [11-14].

The reasons for poor adherence and persistence to LLT are complex and likely encompass many of the predictors that have earlier been recognized as important in research on adherence patterns, such as depression, cognitive impairment, treatment of asymptomatic disease, lack of belief, side effects, inadequate follow-up, poor healthcare provider-patient relationship and cost [15]. In a large survey on adherence in $>10,000$ individuals in the USA who were treated with statins, by far the most common reason for discontinuing treatment was perceived muscle pain $(60 \%)$, followed by the cost of medication (16\%) [16]. Several other predictors of adherence and persistence to LLT, such as the influence of sociodemographic factors, have previously been investigated, but with conflicting and mixed results, and the studies did not specifically address adherence in individuals with T1D [17-20]. Socioeconomic status (SES) has been recognized as a powerful predictor of health [21]. SES is a composite measure of an individual's sociological and economic position in society, and variables of income, occupation and education are usually included when measuring SES, but other factors, such as psychosocial variables, can also be of importance in providing a more comprehensive picture [22]. SES has in an earlier study been associated with a significantly elevated risk for CVD and cardiovascular death in individuals with T1D [23]. In that study, marital status, educational level and income were recognized as socioeconomic factors that had an influence on cardiovascular risk in T1D. Thus, the aim of this study was to assess the association between SES, gender and age and adherence and non-persistence (i.e. discontinuation) of LLT in individuals with T1D who are novel users of LLT.

\section{METHODS}

\section{Study Population}

We conducted a cohort study, with a retrospective design and prospective approach, on individuals with T1D in the Swedish National Diabetes Register (NDR) who were aged $\geq$ 18 years of age and who had initiated LLT between 1 July 2006 and 31 December 2010. T1D was defined on the basis of a diagnosis of diabetes before the age of 30 years and treatment with insulin alone. This cohort has previously been investigated for the relation between adherence to LLT and cardiovascular outcomes and were then followed for 18 months [14]. In the present study, the patients were followed for 36 months after initiation of LLT up to the first day of multi-dose dispensed medicines, death or migration, leading to censoring from the study. Refill adherence to LLT and discontinuation of LLT were measured for all participants after 18 and 36 months.

We identified 16,864 individuals with T1D registered in the NDR who had filled at least one prescription for LLT between 1 July 2006 and 31 December 2010. To include only novel users of LLT, individuals who filled a prescription of LLT within 365 days prior to inclusion were excluded. Further exclusion criteria were individuals with prescription for lipid-lowering extemporaneous preparations, individuals with prescriptions lacking information on package size and individuals with prescriptions for multidose dispensed LLT. Those with prescription for monotherapy of bile acid sequestrants were excluded since bile sequestrants are often prescribed for indications other than hyperlipidemia [24]. Individuals on combination therapy, unless bile sequestrants, were excluded, as were those who had more than one substance or more than one strength of the same substance dispensed on the same date, or if a prescription for a previously filled substance or strength was filled once more within 45 days after the previous supply ended and another substance or strength was dispensed in between. Multiple lipid-lowering substances in the same 
product were considered monotherapy. After implementation of the exclusion criteria, 6192 and 6122 individuals were included in the study for assessment of refill adherence and discontinuation of LLT at 18 and 36 months, respectively.

\section{Measurements of adherence and persistence}

For measurements of adherence and persistence to LLT, we used an algorithm defined in a previous study investigating adherence in individuals with type 2 diabetes [10]. There are several ways to measure adherence to medication $[15,25]$. In the present study, refill adherence was investigated utilizing register data for pharmacy claims to measure the medication possession ratio (MPR), i.e. the proportion of days with medicines on hand during the observation period of 18 and 36 months. Nonpersistence to LLT was evaluated by calculating the proportion of discontinuers of LLT within 18 and 36 months. The duration of each prescription was determined by dividing the number of filled units (e.g. tablets) by the interpreted daily dosage based on the free text variable. Dosage instructions stating the number of doses per day were considered to be interpretable. To interpret the free text variable we developed an algorithm, which we then validated on a random sample of $5 \%$ of the dosage instructions and found $98 \%$ concordance.

To calculate MPR, the total days' supply was divided by the total number of observation days. MPR was calculated as a continuous variable and as dichotomized by creating a cutoff value, with $>80 \%$ defined as high adherence and $\leq 80 \%$ as low adherence. The cutoff value was decided upon based on other studies using $80 \%$ as a measure of high and low adherence to therapy. An $80 \%$ cutoff also represents the threshold above which the benefits of medication with LLT, mainly statins, become obvious in terms of prevention from cardiovascular disease and death $[26,27]$.

To calculate the discontinuation rate, we divided the number of patients who discontinued treatment by the total number of patients who were persistent, at 18 and 36 months, respectively. Discontinuation was defined as a gap of at least 180 days between the supplies of two filled prescriptions for LLT, representing two refills within the Swedish reimbursement system. The discontinuation date was the last day with medicines on hand before the discontinuation gap.

\section{Data Sources}

Data were obtained from registers that have nationwide coverage and linked on individual level using the unique Swedish personal identity number. Clinical baseline characteristics were obtained from the NDR [28]. All patients had provided informed consent to be included in the register. The Longitudinal Integration Database for Health Insurance and Labor Market Studies (LISA; administered by Statistics Sweden) provided demographic and socioeconomic data [29].

The Swedish Prescribed Drug Register (SPDR) has since 1 July 2005 individualized its data on all prescriptions filled in Sweden and has been earlier characterized in a study by Wettermark et al. [30]. The SPDR provided us with information on age, sex, specific drug, package size, date of dispensing and free text dosage instructions from the prescriber [30].

The Swedish National Patient Register (NPR) includes mandatory information on all principal and secondary hospital discharge diagnoses and outpatient specialist visits, and compiles data such as date of contact and diagnostic codes and procedure codes classified according to the International Classification Disease (ICD) system. The NPR has nationwide coverage since 1987. For this study, we used ICD-10 with documented discharge diagnoses since 1997 to acquire information on CVD comorbidities. The diagnoses in the NPR of acute myocardial infarction, coronary heart disease, hospitalization for heart failure, atrial fibrillation and stroke have been validated [31, 32]. The Cause of Death Register, which is based on death certificates, provided data on date and cause of death [33]. 
The data in the Swedish NDR, the SPDR, the LISA database, the Cause of Death Register and the Swedish NPR are all regulated under the General Data Protection Regulation and the laws regulating electronic medical record data and are not open sources. The data can only be accessed for research purposes after ethical approval. The study was approved by the Regional Ethics Review Board at the University of Gothenburg, Gothenburg, Sweden (EPN Diary Numbers: 563-12 and 776-14).

\section{Variables at Baseline}

\section{Patient Characteristics, Biomarkers and Treatments Derived from the NDR}

Data on age, sex, diabetes duration and body mass index were collected from the NDR. Smoking was coded as present if the patient was a current smoker. Physical activity was dichotomized into low (exercise for 30 min less than once a week) or high level (exercise for $30 \mathrm{~min}$ more than 1-2 times per week). Biomarkers were hemoglobin A1c (measured in $\mathrm{mmol} / \mathrm{mol}$ ), triglycerides, LDL-, high-density lipoprotein-cholesterol (measured in $\mathrm{mmol} / \mathrm{L}$ ) and glomerular filtration rate estimated with the Modification of Diet in Renal Disease Study (MDRD) equation (34). Method of insulin delivery was defined as either multiple daily injections or use of continuous subcutaneous insulin infusion. The use of antihypertensive medications, acetylsalicylic acid (ASA) and anticoagulants (excluding ASA) were dichotomized. Baseline data were collected up to 2 years before inclusion with the last observation carried forward.

\section{Socioeconomic Variables Derived from the LISA Database}

Data on marital status, disposable individual income (in hundreds of Swedish kronor; most recent annual income), highest educational level and country of birth were obtained from the LISA database using the value closest to inclusion. Marital categories were unmarried, married, divorced or widowed, and co-habitation was considered to be unmarried. Disposable income was stratified into quartiles (Q1-4), with Q1 being the lowest income level. Education was stratified into compulsory school or lower ( $\leq 9$ years), upper secondary school (10-12 years) and college level ( $>12$ years, college/university). Depending on country of birth, immigrant status was dichotomized as Swedish native or immigrant.

\section{Data on Previous CVD}

Information on previous CVD was retrieved before inclusion date back to 1997 with last observation carried forward. CVD was a composite of myocardial infarction, unstable angina, percutaneous coronary intervention (PCI), coronary artery bypass grafting (CABG), stroke and peripheral vascular disease (PVD), and assessed by the following ICD-10 codes: myocardial infarction (ICD-10 code I21); unstable angina (I20.0); PCI and/or CABG, coronary heart disease (I20-I25); stroke defined as cerebral infarction, intracerebral haemorrhage or unspecified stroke (I61, I63, I64). PVD was defined as peripheral atherosclerosis in the arteries of the extremities (I70.2, I73.9, I79.2) or diabetes mellitus with complications in the peripheral arteries (ICD-10 codes E10.5, E11.5, E14.5).

\section{Statistical Analyses}

The descriptive data are presented using standard descriptive statistics, such as the mean, standard deviation, counts and percentages. Missing data were imputed using multiple imputation based on clinical characteristics when available, pre-index treatments and comorbidities. Ten imputed data sets were created using multiple chained equations and analyzed separately before pooling the analysis results using Rubin's rules. A multivariate logistic regression was then performed to analyze the impact of gender, age, smoking habits, physical activity and socioeconomic status to refill adherence and discontinuation, comparing the group with MPR $>80 \%$ to the group with $\mathrm{MPR} \leq 80 \%$, and discontinuers versus continuers of LLT at 18 and 36 months after initiation of LLT. The analyses were adjusted for age, gender, smoking, physical activity, 
Table 1 Baseline characteristics for the entire study population at index, for individuals with medication possession ratio $\leq$ $80 \%$ and $>80 \%$ and for discontinuers and continuers of lipid-lowering therapy (LLT) at 18 months after initiation of LLT

\begin{tabular}{|c|c|c|c|c|c|}
\hline \multirow[t]{2}{*}{ Variables } & \multirow{2}{*}{$\begin{array}{l}\text { All } \\
(N=6192)\end{array}$} & \multicolumn{4}{|c|}{18 months of LLT } \\
\hline & & $\begin{array}{l}\text { MPR } \leq 80 \% \\
(N=2970)\end{array}$ & $\begin{array}{l}\text { MPR > 80 } \\
(N=3222)\end{array}$ & $\begin{array}{l}\text { Discontinuers } \\
(N=1653)\end{array}$ & $\begin{array}{l}\text { Continuers } \\
(N=4539)\end{array}$ \\
\hline \multicolumn{6}{|l|}{ Patient characteristics } \\
\hline Age, years & $45 \pm 12$ & $43 \pm 12$ & $47 \pm 12$ & $42 \pm 12$ & $46 \pm 12$ \\
\hline Gender, male & $3559(58)$ & $1785(60)$ & $1774(55)$ & $1012(61)$ & $2547(56)$ \\
\hline $\begin{array}{l}\text { Diabetes duration, } \\
\text { years }\end{array}$ & $29 \pm 14$ & $27 \pm 13$ & $31 \pm 14$ & $26 \pm 13$ & $27 \pm 13$ \\
\hline BMI, $\mathrm{kg} / \mathrm{m}^{2}$ & $26.3 \pm 4.2$ & $26.4 \pm 4.2$ & $26.3 \pm 4.2$ & $26.3 \pm 4.3$ & $26.4 \pm 4.2$ \\
\hline Smokers & $651(13)$ & $352(15)$ & $299(11)$ & $209(17)$ & $442(12)$ \\
\hline Physically inactive $^{a}$ & $891(22)$ & $430(22)$ & $461(21)$ & $253(24)$ & $638(21)$ \\
\hline \multicolumn{6}{|l|}{ Biomarkers } \\
\hline $\mathrm{HbAlc}, \mathrm{mmol} / \mathrm{mol}$ & $66 \pm 14$ & $67 \pm 14$ & $64 \pm 13$ & $68 \pm 14$ & $65 \pm 13$ \\
\hline HbAlc, \% & $8.1 \pm 3.4$ & $8.3 \pm 3.4$ & $8.0 \pm 3.4$ & $8.3 \pm 3.5$ & $8.1 \pm 3.4$ \\
\hline $\begin{array}{l}\text { Systolic blood pressure, } \\
\mathrm{mmHg}\end{array}$ & $130 \pm 16$ & $129 \pm 16$ & $130 \pm 15$ & $129 \pm 16$ & $130 \pm 16$ \\
\hline $\begin{array}{l}\text { Diastolic blood } \\
\text { pressure, } \mathrm{mmHg}\end{array}$ & $75 \pm 9$ & $75 \pm 9$ & $74 \pm 9$ & $75 \pm 9$ & $74 \pm 9$ \\
\hline $\begin{array}{l}\text { LDL-cholesterol, } \\
\mathrm{mmol} / \mathrm{L}\end{array}$ & $3.3 \pm 0.8$ & $3.4 \pm 0.8$ & $3.2 \pm 0.7$ & $3.4 \pm 0.8$ & $3.3 \pm 0.7$ \\
\hline $\begin{array}{l}\text { HDL-cholesterol, } \\
\mathrm{mmol} / \mathrm{L}\end{array}$ & $1.6 \pm 0.5$ & $1.6 \pm 0.5$ & $1.6 \pm 0.5$ & $1.6 \pm 0.5$ & $1.6 \pm 0.5$ \\
\hline Triglycerides, $\mathrm{mmol} / \mathrm{L}$ & $1.2 \pm 0.9$ & $1.3 \pm 0.9$ & $1.2 \pm 0.8$ & $1.3 \pm 0.9$ & $1.2 \pm 0.8$ \\
\hline $\mathrm{eGFR}, \mathrm{mL} / \mathrm{min}$ & $91 \pm 25$ & $93 \pm 25$ & $89 \pm 24$ & $94 \pm 26$ & $90 \pm 24$ \\
\hline \multicolumn{6}{|l|}{ Treatment } \\
\hline Multiple aaily injection & $3891(84)$ & $1825(83)$ & $2066(84)$ & $1005(84)$ & $2886(84)$ \\
\hline Insulin pump therapy & $761(16)$ & $366(17)$ & $395(16)$ & $194(16)$ & $567(16)$ \\
\hline $\begin{array}{l}\text { Antihypertensive } \\
\text { medication }\end{array}$ & $2642(43)$ & $992(33)$ & $1650(51)$ & $526(32)$ & $2116(47)$ \\
\hline ASA & $982(16)$ & $356(12)$ & $626(19)$ & $178(11)$ & $804(18)$ \\
\hline Previous disease & & & & & \\
\hline
\end{tabular}


Table 1 continued

\begin{tabular}{llllll}
\hline Variables & $\begin{array}{l}\text { All } \\
(\boldsymbol{N}=\mathbf{6 1 9 2})\end{array}$ & \multicolumn{2}{l}{$\mathbf{1 8}$ months of LLT } \\
\cline { 2 - 6 } & $\begin{array}{l}\text { MPR } \mathbf{5 8 0} \% \\
(\boldsymbol{N}=\mathbf{2 9 7 0})\end{array}$ & $\begin{array}{l}\text { MPR }>\mathbf{8 0} \\
(\boldsymbol{N}=\mathbf{3 2 2 2})\end{array}$ & $\begin{array}{l}\text { Discontinuers } \\
(\boldsymbol{N}=\mathbf{1 6 5 3})\end{array}$ & $\begin{array}{l}\text { Continuers } \\
(\boldsymbol{N}=\mathbf{4 5 3 9})\end{array}$ \\
\hline CVD & $559(9.0)$ & $201(6.8)$ & $358(11.1)$ & $124(7.5)$ & $435(9.6)$ \\
\hline
\end{tabular}

Data are presented as means \pm standard deviation (SD) for continuous variables and as the number $N$ with the percentage in parentheses for categorical variables

$M P R$ Medication Possession Ratio, BMI body mass index, HbAlc glycated hemoglobin, $L D L$ low-density lipoprotein, $H D L$ high-density lipoprotein, eGFR estimated glomerular filtration rate, $A S A$ acetylsalicylic acid, $C V D$ cardiovascular disease

a Physically inactive refers to low physical activity, consisting of exercise of 30 min duration less than once a week

previous CVD and socioeconomic status, as presented in Table 2 . Results are presented in terms of odds ratios (ORs) with 95\% confidence intervals (CIs) and $p$ values.

All hypothesis tests were evaluated using a $5 \%$ significance level. The analyses were performed using SAS version 9.4 (SAS Institute, Cary, NC, USA).

\section{RESULTS}

In total, 6192 individuals with T1D initiated LLT between 2006 and 2010 and were eligible for enrollment in the study. The characteristics of all participants initiating LLT treatment at baseline and the distribution of the baseline variables by adherence and non-persistence to LLT at 18 months are given in Table 1; the distribution of these variables at 36 months is given in Electronic Supplementary Material (ESM) Table 1. Of these novel users, 99\% $(n=6132)$ started treatment with a statin, mainly simvastatin, which accounted for over 94\% of the prescriptions for LLT, while atorvastatin made up $3.4 \%$ of prescriptions (see ESM Table 2).

The mean MPR in the overall cohort over 18 months was $72 \pm 28 \%$, and $52 \%$ had an MPR $>80 \%$. After 36 months $48 \%$ had an MPR $>80 \%$. Within 18 months $27 \%$ of the participants had discontinued with LLT, and at 36 months the proportion of discontinuers had increased to $42 \%$.
In the group with high adherence the proportion of individuals with previous CVD was higher at 18 months (11.1 vs. $6.8 \%)$ than in the low adherence group (see Table 1). Individuals with a history of CVD also discontinued LLT to a lesser extent. Those treated with antihypertensives and those treated with ASA were also more frequently found in the group of high adherence and less often among the discontinuers. Smokers on the other hand were more frequent in the group with lower adherence $(15$ vs. $11 \%)$ and in the group of discontinuers (17 vs. $12 \%)$.

Table 2 shows the distribution of gender, age, socioeconomic variables (including marital status, education, income and country of origin) and previous CVD in individuals with high adherence (MPR $>80 \%$ ) at 18 and 36 months, and in individuals discontinuing treatment within 18 and 36 months, respectively.

For detailed results from the multivariate logistic regression, see Figs. 1 and 2 and ESM Tables 3 and 4 for the ORs with 95\% CIs at 18 and 36 months.

After 18 months, women were more likely to be adherent (MPR $>80 \%$ ) than men (OR 1.05, $p=0.0005)$, but at 36 months there was no difference in terms of adherence between genders. Adherence increased incrementally with age, with the largest impact seen in individuals aged $\geq 53$ years compared to those aged < 36 years (OR 1.30, $p<0.0001$ ) at 36 months. Compared to married persons, divorced individuals were less adherent consistently over 
Table 2 Distribution of gender, age and socioeconomic variables in individuals with high adherence $(\mathrm{MPR}>80 \%)$ after 18 and 36 months, and in individuals discontinuing treatment within 18 and 36 months

\begin{tabular}{|c|c|c|c|c|}
\hline \multirow[t]{2}{*}{ Variables } & \multicolumn{2}{|c|}{ Individuals with $\mathrm{MPR}>\mathbf{8 0 \%}$} & \multicolumn{2}{|c|}{ Individuals discontinuing LLT } \\
\hline & $\begin{array}{l}18 \text { months } \\
(N=3222)\end{array}$ & $\begin{array}{l}36 \text { months } \\
(N=2953)\end{array}$ & $\begin{array}{l}18 \text { months } \\
(N=1653)\end{array}$ & 36 months $(N=2577)$ \\
\hline \multicolumn{5}{|l|}{ Gender } \\
\hline Male & $1774(50)$ & $1668(47)$ & $1012(28)$ & $1490(42)$ \\
\hline Female & $1448(55)$ & $1285(49)$ & $641(24)$ & $1087(42)$ \\
\hline \multicolumn{5}{|l|}{ Age group, years } \\
\hline$<36$ & $649(41)$ & $534(34)$ & $564(35)$ & $870(55)$ \\
\hline $36-43$ & $734(47)$ & $686(44)$ & $441(28)$ & $660(43)$ \\
\hline $44-52$ & $838(56)$ & $780(52)$ & $361(24)$ & $571(38)$ \\
\hline$>52$ & $1001(65)$ & $953(62)$ & $287(19)$ & $476(31)$ \\
\hline \multicolumn{5}{|l|}{ Marital status } \\
\hline Married & $1580(56)$ & $1484(53)$ & $653(23)$ & $1022(37)$ \\
\hline Unmarried & $1196(48)$ & $1053(42)$ & $759(30)$ & $1169(47)$ \\
\hline Divorced & $391(51)$ & $361(47)$ & $221(29)$ & $347(45)$ \\
\hline Widowed & $52(57)$ & $54(59)$ & $17(19)$ & $33(37)$ \\
\hline \multicolumn{5}{|l|}{ Education } \\
\hline$\leq 9$ years & $560(53)$ & $527(50)$ & $275(26)$ & $416(40)$ \\
\hline $10-12$ years & $1675(51)$ & $1535(46)$ & $930(28)$ & $1427(44)$ \\
\hline College/ & $968(54)$ & $874(49)$ & $435(24)$ & $717(40)$ \\
\hline University & & & & \\
\hline \multicolumn{5}{|l|}{ Income $(\mathrm{SEK})^{\mathrm{a}}$} \\
\hline Q1（ $\leq 1368)$ & $807(52)$ & $705(45)$ & $447(29)$ & 707 (47) \\
\hline Q2 (1369-1944) & $807(52)$ & $742(48)$ & $425(28)$ & $669(44)$ \\
\hline Q3 (1945-2517) & $805(52)$ & $754(49)$ & $402(26)$ & $620(40)$ \\
\hline Q4 ( $\geq 2518)$ & $800(52)$ & $751(49)$ & $376(24)$ & $575(38)$ \\
\hline \multicolumn{5}{|l|}{ Country of origin } \\
\hline Rest of the World & $206(47)$ & $170(39)$ & $150(34)$ & $232(53)$ \\
\hline Sweden & $3016(52)$ & $2783(48)$ & $1503(26)$ & $2345(41)$ \\
\hline \multicolumn{5}{|l|}{ Previous CVD } \\
\hline No & $2864(51)$ & $2620(47)$ & $1529(27)$ & $2378(43)$ \\
\hline
\end{tabular}


Table 2 continued

\begin{tabular}{llllll}
\hline Variables & \multicolumn{2}{l}{ Individuals with } & MPR $>\mathbf{8 0 \%}$ & & \multicolumn{2}{l}{ Individuals discontinuing $\mathbf{L L T}$} \\
\cline { 2 - 3 } & $\begin{array}{l}\mathbf{1 8} \text { months } \\
(\boldsymbol{N}=\mathbf{3 2 2 2})\end{array}$ & $\begin{array}{l}\mathbf{3 6} \text { months } \\
(\boldsymbol{N}=\mathbf{2 9 5 3})\end{array}$ & & $\begin{array}{l}\mathbf{1 8} \text { months } \\
(\boldsymbol{N}=\mathbf{1 6 5 3})\end{array}$ & $\mathbf{3 6}$ months $(\boldsymbol{N}=\mathbf{2 5 7 7})$ \\
\hline Yes & $358(64)$ & $333(60)$ & & $124(22)$ & $199(36)$ \\
\hline
\end{tabular}

All data are presented as the number $(N)$ and proportion (\%; in parentheses) of individuals with MPR $>80 \%$ and as discontinuers compared to all individuals in the same category at 18 and 36 months, respectively.

${ }^{a}$ Income is individual disposable income given in hundreds of Swedish kronor (SEK), divided into quartiles (Q), with the lowest quartile being Q1

time. More individuals born in Sweden had an MPR $>80 \%($ OR 1.10, $p=0.0002)$ at 36 months than those immigrating to Sweden. Smokers were less adherent than non-smokers at 18 and 36 months. Being or not being physically active did not appear to have an association to adherence in our study.

Regarding non-persistence, i.e. discontinuation of LLT, women were less prone to discontinue compared to men at 18 months (OR 0.95, $p=0.0004$ ), but the difference between genders was again lost at 36 months (Fig. 2). There was an incremental pattern of discontinuation dependent on age group, with the oldest age group ( $\geq 53$ years) being the most persistent at 18 and 36 months (OR 0.85 and OR 0.80, respectively, $p<0.0001$ ) compared to the youngest age group ( $<36$ years). Divorced individuals discontinued LLT more frequently than married persons. The influence of disposable income became significant in the two higher income quartiles (Q3 and Q4), with fewer individuals in these two quartiles discontinuing LLT compared to the lowest quartile at 18 and 36 months. People born in Sweden were less prone, compared to people immigrating to Sweden, to discontinue LLT (OR 0.89, $p<0.0001)$ at 36 months. Level of education was not associated with discontinuation of LLT. Smokers discontinued LLT more often than non-smokers, while physical activity was not associated with discontinuation of LLT.

\section{DISCUSSION}

In this study, we demonstrate that both adherence and non-persistence to medication were influenced by time passed after initiation of LLT. At 18 months, the proportion of patients with high adherence (MPR $>80 \%$ ) decreased from 52 to $48 \%$, and at 36 months, the proportion of those who discontinued LLT increased from 27 to $42 \%$. Gender, age, marital status, income and country of origin were associated to level of refill adherence and persistence to LLT in individuals with T1D. Our results also showed that smoking habits significantly influenced adherence behaviors.

The relation between SES and the prevalence of cardiovascular risk factors and higher cardiovascular mortality is well established $[21,22]$. SES is traditionally evaluated by measures that include a combination of economy, education and occupation, but other mediators of SES, such as psychosocial measures, can be important contributors to a more comprehensive picture [22]. The relationship between SES and CVD has also been confirmed in individuals with T1D, who are already at increased risk for cardiovascular events due to their diabetes condition per se $[23,35,36]$.

Several studies have addressed the problem with suboptimal adherence to LLT, mainly statins, and evaluated predictors of adherence and persistence, although these focused on other patient categories than on those with T1D $[17,20]$. Comparing studies of adherence and 


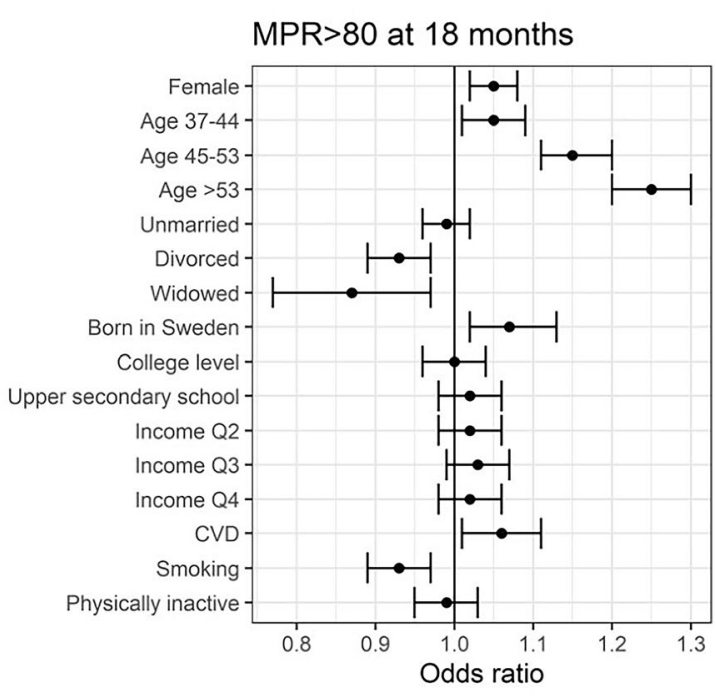

Fig. 1 The effect of gender, age and socioeconomic parameters on medication possession ratio $(M P R)>80 \%$ at 18 and 36 months, presented as adjusted odds ratios with $95 \%$ confidences intervals. Analyses were based on logistic regression and adjusted for gender, age group, marital status, level of education and income, country of origin, previous cardiovascular disease $(C V D)$, smoking habits and physical activity. Age groups were compared to individuals aged $<36$, each marital status to married,

persistence is a cumbersome task since many studies not only differ in methodology and in follow-up time, but there is also a timeline to consider, with changes of treatment guidelines and cost of medication. Such circumstances can alter adherence behaviors in patients as well as adherence to treatment guidelines by healthcare providers. In the present study, we have focused on evaluating sociodemographic factors as predictors of refill adherence and persistence in individuals who initiated LLT between 2006 and 2010. This was a period when the patent had expired (2003) for the most prescribed LLT in this study (simvastatin), and less expensive generic substitutes were available, which could potentially affect refill adherence and persistence to LLT.

However, in terms of rates of discontinuation and low adherence, our results are well in line with those of earlier studies. Penning-van Beest et al. investigated persistence in 59,094 new users of statins between 1991 and 2004 and found a striking 53\% discontinuation rate of

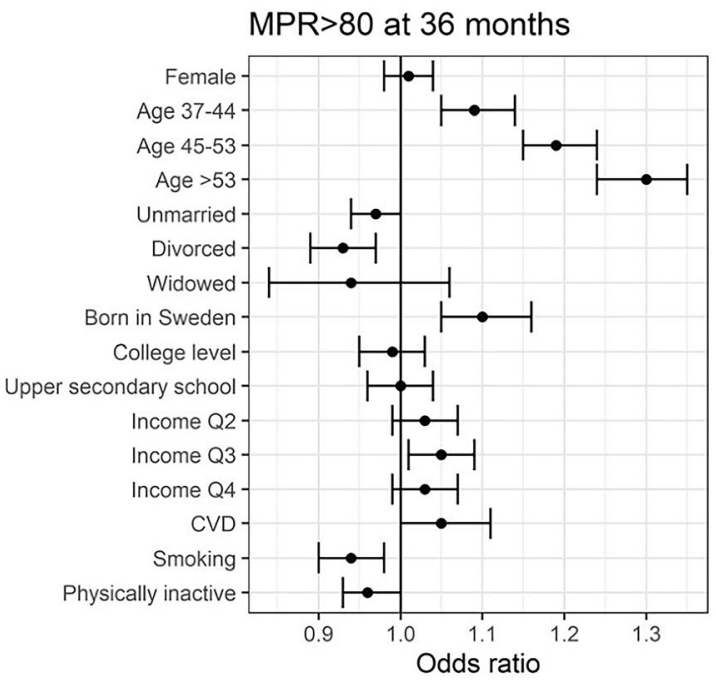

educational level to elementary school and income to the lowest quartile $(Q)$ of income. Odds ratio of 1 represents no difference between the compared groups. College level included university, and upper secondary school included studies beyond compulsory school (10-12 years). Physical inactivity equals low physical activity with exercise of $30 \mathrm{~min}$ less than once a week

statin therapy within 2 years [37]. In a study from Scotland of adherence to statin treatment in 6462 patients with type 2 diabetes, only $41 \%$ covered $>80 \%$ of the days with statin medication 5 years after initiation of therapy [38]. In our study, $42 \%$ had discontinued LLT within 36 months of treatment initiation. In studies that have followed adherence and persistence for a longer term, there is, as also found in our study, a trend for decreasing adherence and persistence over time $[39,40]$.

It is well known that adherence levels to and persistence with LLT increase with the presence of risk factors for future cardiac events, such as being treated for diabetes, hypertension or having a history of CVD [10, 12, 41]. Karlsson et al. [10] studied adherence to LLT in $>97,000$ individuals with type 2 diabetes and found that the mean refill adherence was $71 \%$ after the 3 -year observation period, which is well in line with our study, but that $55 \%$ had an MPR > $80 \%$ compared to $48 \%$ in individuals with T1D in our study. The reason for this difference is 


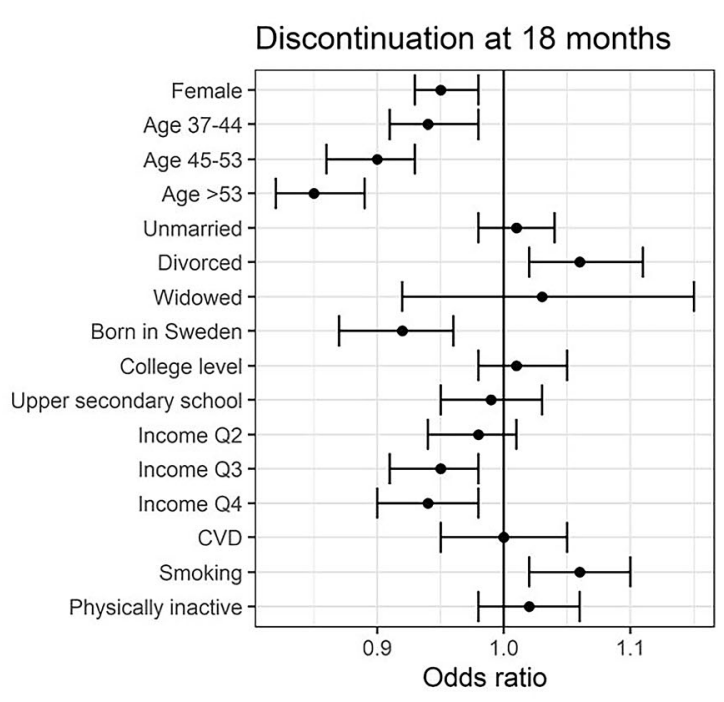

Fig. 2 The effect of gender, age and socioeconomic parameters on discontinuation at 18 and 36 months, presented as adjusted odds ratios with $95 \%$ confidence intervals. Analyses were based on logistic regression and adjusted for gender, age group, marital status, level of education and income, country of origin, previous CVD, smoking habits and physical activity. Age groups were compared to individuals aged $<36$ years, each marital status to married, educational level to elementary school

likely due to the individuals in our cohort being younger (mean age) and having fewer concomitant medications and comorbidity, two factors that influenced the adherence behavior among the patients with type 2 diabetes in the Karlsson et al. study [10]. Also, in our study we observed that a higher proportion of participants with a high MPR $>80 \%$ and those who continued on LLT took antihypertensive medication and had previous CVD. However, in the analyses adjusted for age, gender, socioeconomic factors, smoking habits and physical activity, previous CVD was associated with high adherence to but not persistence with LLT.

Regarding gender, earlier studies present mixed results regarding the prediction of adherence behavior according to gender, with both higher and lower adherence levels reported for women, as well as a difference between adherence and persistence $[18,20]$. In a metaanalysis of 22 cohort studies, women were more likely to be non-adherent, which is in disagreement with our study results, where women

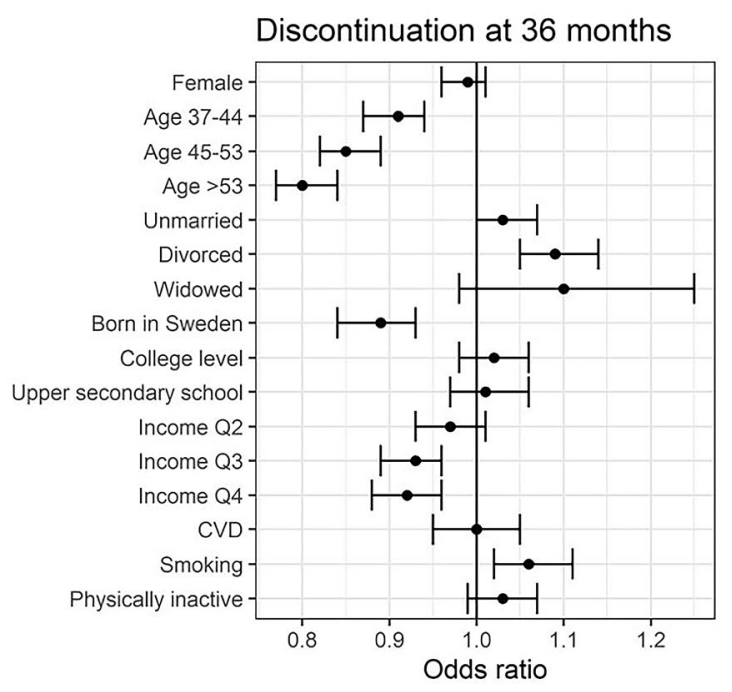

and income to the lowest quartile of income (Q1). Odds ratio of 1 represents no difference between the compared groups. College level included university, and upper secondary school included studies beyond compulsory school (10-12 years). Physical inactivity equals low physical activity with exercise of $30 \mathrm{~min}$ less than once a week

were more adherent to LLT and continued with LLT more often than men in the first 18 months of follow-up [17]. On the other hand, in our study gender had no impact on either adherence or discontinuation after 36 months.

Previous studies also report conflicting results concerning the influence of age on adherence. Both lower and higher adherence to LLT depending on age have been observed $[20,38,42]$. In the above-mentioned metaanalysis [17], a $U$-shaped age association was revealed in which those above 70 years and those aged $<50$ years had a lower adherence than those between 50 and 70 years of age. In our study, older participants were more adherent than the younger ones in an incremental pattern and they also continued with LLT to a greater extent; this trend was even more pronounced after 36 months of follow-up. Adherence rates are known to be higher in individuals with previous CVD than in individuals without a history of CVD, and although we adjusted for CVD, there could be other comorbidities present in 
individuals in the higher age groups that influence them to follow prescriptions to a greater extent. However, since the participants in the present study were young (mean age 45 years), with the highest age quartile starting at age $\geq 53$ years, we cannot rule out the possibility that there is a $U$-shape pattern with lower adherence appearing above the highest threshold in our cohort also.

In terms of socioeconomic influence on refill adherence and persistence, authors of earlier studies on predictors have proposed a link between low SES and low adherence. Many of these studies were based on contextual measures of SES, which is in contrast to our study where we present information on income, education and marital status at an individual level [18-20]. The authors of several studies point out the cost of medication and low household income as reasons for non-adherence and discontinuation of LLT [18, 19]. Income had an impact in the present study, where those having a higher income were less prone to discontinue LLT; however, the rate of adherence was not influenced to the same degree. In our study we collected information on disposable income. However, disposable income may not capture an individual's financial resources to a full extent, particularly not household income, possibly attenuating the association between adherence and income. The effect of disposable income on adherence and persistence could also be attenuated by the fact that social benefits in Sweden provide almost complete economic coverage for healthcare and medications with fixed co-pays up to a ceiling [43]. Even so, in Denmark, a country with social benefits similar to those in Sweden, low income had a significant impact on persistence to statins in patients after admission for a cardiovascular event [44].

In our study divorced individuals were less adherent to and discontinued LLT more often than married persons. There are few other studies investigating marital status in relation to statin adherence. Kulkarni et al. described lower 1-year adherence to statins in unmarried patients who had been discharged after a coronary artery disease event, and a cross-sectional study on 247 Lebanese patients with dyslipidemia also showed lower adherence in divorced individuals $[45,46]$. Both studies also indicated an effect of educational level on adherence, which could not be seen in our study. Rawshani et al. investigated the impact of SES on CVD and mortality in individuals with T1D and found that lower levels of education as well as low income were associated with a higher risk for CVD, but that the effect of education was attenuated after adjusting for income [23]. This study also showed that immigrants with T1D had a $10-40 \%$ lower risk of cardiovascular outcomes than native Swedes with T1D. This is an intriguing finding, especially in the light of our study where immigrants had a substantially lower refill adherence and higher discontinuation rate of LLT. Reasons for the lower adherence to and persistence with LLT among immigrants to Sweden when compared to native Swedes could be multifaceted and include factors such as difficulties in understanding instructions from the healthcare providers, lower health literacy, as well as cultural and financial barriers. Speaking another language than English was also found to be one of the strongest predictors for low adherence in a study from Australia on statin adherence in the general population [47].

In our study, we also assessed the association between a healthy lifestyle and statin adherence, using smoking habits and physical activity as proxies for healthy behavior. We found no association between degree of physical activity and adherence to or persistence with statins. One could argue that being a smoker should make a patient more inclined to adhere to cardioprotective treatment, but in our study, smokers were both less adherent and discontinued LLT to a higher extent than non-smokers. Lack of health literacy could be one explanation for this finding [48].

\section{Strengths and Limitations}

This study has several strengths. It has a nationwide design with a large sample of individuals with T1D, representing a wide distribution of socioeconomic factors. Our register-based study provides detailed data on SES, with information 
at the individual level as well as information on patient characteristics, including healthy lifestyle behaviors, cardiovascular risk factors and previous CVD. This information allowed us to reflect on the use of LLT in a real-world setting, since prescription refill adherence is one of the most reliable objective measures of adherence in large patient groups with long-term treatments of chronic conditions [15].

There are also limitations, including the possibility of unmeasured confounders not considered, such as traits like depression and cognitive impairment, that may contribute to changed adherence behaviors. We also lacked information on some other important reasons for discontinuation of medication, such as adverse reactions resulting in termination of treatment by either the prescriber and/or patient, without switching to another lipidlowering drug. As a matter of fact, in a large survey investigating statin adherence in 10,138 patients, perceived muscle pain was the far most common reason for non-persistence, accounting for $60 \%$ of cases of discontinuation, followed by cost and perceived lack of efficacy [19].

\section{CONCLUSIONS}

In this nation-wide register-based study of individuals with T1D initiating LLT, low adherence to and persistence with LLT were associated with male gender, younger age, marital status (as in being divorced or single), smoking habits and having a country of origin other than Sweden. We also observed a worrying trend of declining adherence to and persistence with to LLT over time. To reach the full potential of cardiovascular protection and reduce the risk for future cardiovascular events, it is important to consider all of the factors that can influence the ability or willingness to follow the LLT regimen and address them during clinical visits.

\section{ACKNOWLEDGEMENTS}

The authors thank the regional NDR coordinators, as well as contributing nurses, physicians, and patients.

Funding. The study, including the journal's Rapid Service Fee, was funded by grants from Emelle foundation, the Gothenburg Society of Medicine and the Swedish state under the agreement between the Swedish government and the county councils, namely the ALF agreement (ALFGBG-698991 and ALFGBG430711). The Swedish Diabetes Association and the Swedish Society of Diabetology support the NDR. The Swedish Association of Local Authorities and Regions funds the NDR.

Authorship. All named authors meet the International Committee of Medical Journal Editors (ICMJE) criteria for authorship for this article, take responsibility for the integrity of the work, and have given their approval for this version to be published.

Author Contributions. Study concept and design: C Hero, SA Karlsson, A-M Svensson, S Franzén, K Andersson-Sundell, B Eliasson, K Eeg-Olofsson. Statistical analyses: M Miftaraj, S Franzén. Interpretation of data: C Hero, SA Karlsson, K Andersson-Sundell, A-M Svensson, B Eliasson, K Eeg-Olofsson, S Franzén. Drafting of manuscript: C Hero and K Eeg-Olofsson. Critical revision and completion of manuscript: all authors. The manuscript has been read and approved by all co-authors.

Prior Presentation. Part of the results were presented as a poster presentation at the EASD Conference in Berlin in October 2018.

Disclosures. Karolina Andersson-Sundell is employed by AstraZeneca. However, the views expressed in this study are her own and not those of AstraZeneca. Soffia Gudbjörnsdottir has received personal fees (lecture fees and research grants) from AstraZeneca, Boehringer Ingelheim, ELI Lilly, MSD, Novo Nordisk and Sanofi. Katarina Eeg-Olofsson has received personal lecture fees from Sanofi, Eli Lilly, Novo Nordisk 
and Abbott, all outside the submitted work. Björn Eliasson reports personal fees from Amgen, AstraZeneca, Boehringer Ingelheim, Eli Lilly, Merck Sharp \& Dohme, Mundipharma, RLS Global and Sanofi, all outside the submitted work. Christel Hero, Sofia Karlsson, Ann-Marie Svensson, Mervete Miftaraj and Stefan Franzén declare no conflict of interest relevant to this article.

Compliance with Ethic Guidelines. The study was approved by the Regional Ethics Review Board at the University of Gothenburg, Gothenburg, Sweden (EPN Diary Numbers: 563-12 and 776-14).

Data Availability. The datasets generated and/or analysed during the current study are not publicly available. The data in the Swedish NDR, the SPDR, The LISA database, The Cause of Death Register and the Swedish NPR are all regulated under the General Data Protection Regulation and the laws regulating electronic medical record data and are not open sources. The data can only be accessed for research purposes after ethical approval. The principal investigator is the guarantor of the integrity of the data.

Open Access. This article is licensed under a Creative Commons Attribution-NonCommercial 4.0 International License, which permits any non-commercial use, sharing, adaptation, distribution and reproduction in any medium or format, as long as you give appropriate credit to the original author(s) and the source, provide a link to the Creative Commons licence, and indicate if changes were made. The images or other third party material in this article are included in the article's Creative Commons licence, unless indicated otherwise in a credit line to the material. If material is not included in the article's Creative Commons licence and your intended use is not permitted by statutory regulation or exceeds the permitted use, you will need to obtain permission directly from the copyright holder. To view a copy of this licence, visit http://creativecommons.org/licenses/by$\mathrm{nc} / 4.0 /$.

\section{REFERENCES}

1. Rawshani A, Rawsani A, Franzén S, et al. Mortality and cardiovascular disease in type 1 and type 2 diabetes. N Engl J Med. 2017;376(15):1407-18.

2. Huo L, Harding JL, Peeters A, Shaw JE, Magliano DJ. Life expectancy of type 1 diabetic patients during 1997-2010: a national Australian registry-based cohort study. Diabetologia. 2016;59(6):1177-85.

3. Rawshani A, Sattar N, Franzén S, et al. Excess mortality and cardiovascular disease in young adults with type 1 diabetes in relation to age at onset: a nationwide, register-based cohort study.Lancet. 2018;392(10146):477-86.

4. Mach F, Baigent C, Catapano AL, et al. 2019 ESC/ EAS Guidelines for the management of dyslipidaemias: lipid modification to reduce cardiovascular risk. Eur Heart J. 2020;41(1):111-88.

5. Disease C, Management R. Standards of medical care in diabetes-2021. Diabetes Care. 2021;44(1): S125-50.

6. Kearney PM, Blackwell L, Collins R, et al. Efficacy of cholesterol-lowering therapy in 18,686 people with diabetes in 14 randomised trials of statins: a metaanalysis. Lancet. 2008;371(9607):117-25.

7. Hero C, Rawshani A, Svensson A-M, et al. Association between use of lipid-lowering therapy and cardiovascular diseases and death in individuals with type 1 diabetes. Diabetes Care. 2016;39(6): 996-1003.

8. Adherence to long-term therapies. Evidence for action. Geneva: World Health Organization; 2003. Essent Drugs Monit. 2005(34):33

9. Vinogradova Y, Coupland C, Brindle P, HippisleyCox J. Discontinuation and restarting in patients on statin treatment: prospective open cohort study using a primary care database. BMJ. 2016. https:// doi.org/10.1136/bmj.i3305.

10. Karlsson SA, Hero C, Eliasson B, et al. Refill adherence and persistence to lipid-lowering medicines in patients with type 2 diabetes: a nation-wide register-based study. Pharmacoepidemiol Drug Saf. 2017;26(10):1220-32.

11. Perreault S, Dragomir A, Blais L, et al. Impact of better adherence to statin agents in the primary prevention of coronary artery disease. Eur J Clin Pharmacol. 2009;65(10):1013-24.

12. Chowdhury R, Khan H, Heydon E, et al. Adherence to cardiovascular therapy: a meta-analysis of 
prevalence and clinical consequences. Eur Heart J. 2013;34(38):2940-8.

13. Karlsson SA, Hero C, Svensson AM, et al. Association between refill adherence to lipid-lowering medications and the risk of cardiovascular disease and mortality in Swedish patients with type 2 diabetes mellitus: a nationwide cohort study. BMJ Open. 2018;8(3): e020309.

14. Hero C, Karlsson SA, Franzén S, et al. Adherence to lipid-lowering therapy and risk for cardiovascular disease and death in type 1 diabetes mellitus: a population-based study from the Swedish National Diabetes Register. BMJ Open Diabetes Res Care. 2020;8(1): e000719.

15. Osterberg L, Blaschke T. Adherence to medication. N Engl J Med. 2005;353(5):487-97.

16. Wei MY, Ito MK, Cohen JD, Brinton EA, Jacobson TA. Predictors of statin adherence, switching, and discontinuation in the USAGE survey: understanding the use of statins in America and gaps in patient education. J Clin Lipidol. 2013;7(5):472-83.

17. Mann DM, Woodward M, Muntner P, Falzon L, Kronish I. Predictors of nonadherence to statins: a systematic review and meta-analysis. Ann Pharmacother. 2010;44(9):1410-21.

18. Chan CD, Shrank HW, Cutler AD, et al. Patient, physician, and payment predictors of statin adherence. Med Care. 2010;48(3):196-202.

19. Wei MY, Ito M, Cohen J, Brinton E, Jacobson T. Predictors of statin adherence, switching, and discontinuation in the usage survey: understanding statin use in America and gaps in patient education*. J Clin Lipidol. 2013;7(3):245-6.

20. Alfian SD, Worawutputtapong P, Schuiling-Veninga $\mathrm{CC}$, et al. Pharmacy-based predictors of non-persistence and non-adherence to statin treatment among patients on oral diabetes medication in the Netherlands. Curr Med Res Opin. 2018;34(6): 1013-19.

21. Mackenbach JP, Stirbu I, Roskam A-JR, et al. Socioeconomic inequalities in health in 22 European countries. New Eng J Med. 2008;358(23): 2468-81.

22. Kaplan GA, Keil JE. Socioeconomic factors and cardiovascular disease: a review of the literature. Circulation. 1993;88(4 Pt 1):1973-98.

23. Rawshani A, Svensson A-M, Rosengren A, Eliasson $\mathrm{B}$, Gudbjörnsdottir S. Impact of socioeconomic status on cardiovascular disease and mortality in 24,947 individuals with type 1 diabetes. Diabetes Care. 2015;38(8):1518.
24. Scaldaferri F, Pizzoferrato M, Ponziani FR, Gasbarrini G, Gasbarrini A. Use and indications of cholestyramine and bile acid sequestrants. Intern Emerg Med. 2013;8(3):205-10.

25. Vrijens B, De Geest S, Hughes DA, et al. A new taxonomy for describing and defining adherence to medications. Br J Clin Pharmacol. 2012;73(5): 691-705.

26. Cramer JA, Benedict Á, Muszbek N, Keskinaslan A, Khan ZM. The significance of compliance and persistence in the treatment of diabetes, hypertension and dyslipidaemia: a review. Int J Clin Pract. 2008;62(1):76-87.

27. Ruokoniemi P, Korhonen MJ, Helin-Salmivaara A, et al. Statin adherence and the risk of major coronary events in patients with diabetes: a nested case-control study. $\mathrm{Br} \mathrm{J}$ Clin Pharmacol. 2011;71(5):766-76.

28. Eliasson B, Gudbjörnsdottir S. Diabetes care-improvement through measurement. Diabetes Res Clin Pract. 2014;106:S291-4.

29. Statistics Sweden. Longitudinal integrated database for health insurance and labour market studies (LISA). http://www.scb.se/lisa-en/. Accessed 1 Apr 2018.

30. Wettermark B, Hammar N, Fored CM, et al. The new Swedish Prescribed Drug Register-Opportunities for pharmacoepidemiological research and experience from the first six months. Pharmacoepidemiol Drug Saf. 2007;16(7):726-35.

31. Ludvigsson J, Andersson E, Ekbom A, et al. External review and validation of the Swedish national inpatient register. BMC Public Health. 2011;11(1): 450.

32. Ingelsson E, Arnlov J, Sundstrom J, Lind L. The validity of a diagnosis of heart failure in a hospital discharge register. Eur J Heart Fail. 2005;7:787-91.

33. Brooke HL, Talbäck M, Hörnblad J, et al. The Swedish cause of death register. Eur J Epidemiol. 2017;32(9):765-73.

34. Levey AS, Bosch JP, Lewis JB, Greene T, Rogers N, Roth D. A more accurate method to estimate glomerular filtration rate from serum creatinine: a new prediction equation. Modification of Diet in Renal Disease Study Group. Ann Intern Med. 1999;130(6):461-70.

35. Secrest AM, Costacou T, Gutelius B, Miller RG, Songer TJ, Orchard TJ. Associations between socioeconomic status and major complications in type 1 diabetes: the Pittsburgh Epidemiology of 
Diabetes Complication (EDC) Study. Ann Epidemiol. 2011;21(5):374-81.

36. Disease C, Management R. Standards of medical care in diabetes-2020. Diabetes Care. 2020;43(Suppl 1):S111.

37. Penning-van Beest FJA, Termorshuizen F, Goettsch WG, Klungel $\mathrm{OH}$, Kastelein JJP, Herings RMC. Adherence to evidence-based statin guidelines reduces the risk of hospitalizations for acute myocardial infarction by $40 \%$ : a cohort study. Eur Heart J. 2007;28(2):154-9.

38. Donnelly LA, Doney ASF, Morris AD, Palmer CNA, Donnan PT. Long-term adherence to statin treatment in diabetes. Diabet Med. 2008;25(7):850-5.

39. Benner JS, Glynn RJ, Mogun H, Neumann PJ, Weinstein MC, Avorn J. Long-term persistence in use of statin therapy in elderly patients. ACC Curr J Rev. 2002;11(6):36.

40. Helin-Salmivaara A, Lavikainen P, Korhonen MJ, et al. Long-term persistence with statin therapy: a nationwide register study in Finland. Clin Ther. 2008;30(Pare 2):2228-40.

41. Avorn J, Monette J, Lacour A, et al. Persistence of use of lipid-lowering medications: a cross-national study. J Am Med Assoc. 1998;279(18):1458-62.

42. Jackevicius CA, Mamdani M, Tu JV. Adherence with statin therapy in elderly patients with and without acute coronary syndromes. JAMA. 2002;288(4): $462-7$.

43. Dental and Pharmaceutical Benefits Agency (TDaPBA). https://www.tlv.se/in-english.html. Accessed 1 Apr 2018.

44. Rasmussen JN, Gislason GH, Rasmussen S, et al. Use of statins and beta-blockers after acute myocardial infarction according to income and education. J Epidemiol Community Health. 2007;61(12): 1091-7.

45. Kulkarni SP, Alexander KP, Lytle B, Heiss G, Peterson ED. Long-term adherence with cardiovascular drug regimens. Am Heart J. 2006;151(1):185-91.

46. Haddad C, Hallit S, Salhab M,et al. Association between adherence to statins, illness perception, treatment satisfaction, and quality of life among Lebanese patients. J Cardiovasc Pharmacol Ther. 2018;23(5):414-22.

47. Warren JR, Falster MO, Fox D, Jorm L. Factors influencing adherence in long-term use of statins. Pharmacoepidemiol Drug Saf. 2013;22(12): 1298-307.

48. Atri S, Sahebihagh M, Jafarabadi M, Behshid M, Ghasempour M, Abri F. The relationship between health literacy and stages of change in smoking behavior among employees of educational health centers of Tabriz University of Medical Sciences (2016). Int J Prevent Med. 2018;9(1):91. 